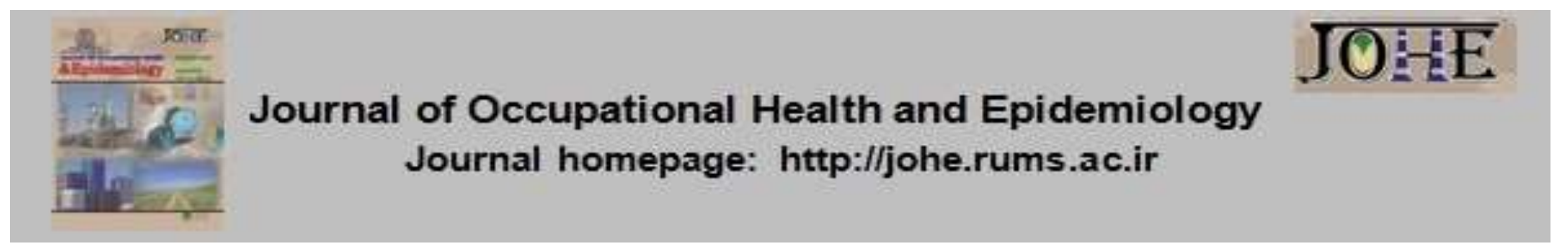

\title{
Individual and professional factors affecting social health of faculty members of Islamic Azad Universities in East Azarbaijan, Iran (2016-2018)
}

\author{
Rahim Abdollahfam ${ }^{1}$, Jahangir Yari Haj Ataloo ${ }^{*}$, Behnam Talebi², Davoud Ebrahimpour ${ }^{3}$ \\ 1- PhD Student of Educational Management, Tabriz Branch, Islamic Azad University, Tabriz, Iran. \\ 2- Assistant Prof., of Educational Management, Tabriz Branch, Islamic Azad University, Tabriz, Iran. \\ 3- Assistant Prof., of Sociology, Tabriz Branch, Islamic Azad University, Tabriz, Iran.
}

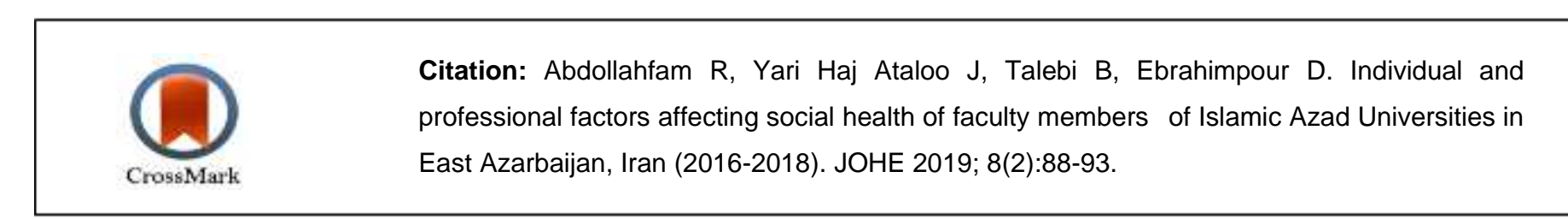

\section{Article Info}

* Corresponding author: Rahim Abdollahfam, E-mail:

john_yari@yahoo.com

Article history

Received: Nov, 2018

Accepted: Mar, 2019

$10.29252 /$ johe.8.2.88

Print ISSN: 2251-8096 Online ISSN: 2252-0902

Peer review under responsibility of Journal of Occupational Health and Epidemiology

\begin{abstract}
Background: Individual and professional features have a positive impact on success, performance improvement, and other behavioral variables in all organizations. Social health is an important components for the employees of every organization. This research was carried out to investigate the effect of individual and professional factors on the social health of faculty members of Islamic Azad universities in East Azarbaijan province, Iran.

Materials and Methods: This is a descriptive-correlational study. The participants of the study were 320 faculty members of Islamic Azad Universities in East Azarbaijan. The data collection tools were standard questionnaires for occupational, personal, and social health factors. Multiple correlation coefficient was used to analyze the data using structural equation modelling in Amos software.

Results: Results revealed that there is a significant positive relationship between professional features and individual factors with social health (i.e., 0.43 at the significance level of 0.002). Furthermore, the correlation coefficients between professional characteristics and individual factors (i.e., feedback, freedom of action, importance at work, identity at work, and difference in skill) and social health changes were significant (with correlation coefficients of $0.730,0.464,0.764,0.423$, and 0.568 , respectively).

Conclusion: Based on the results, it can be concluded that there is a linear correlation among professional features, individual factors, and social health. A better relationship among the individual characteristics can lead to higher social health for faculty members.
\end{abstract}

Keywords: Individual, Job, Health

\section{Introduction}

The importance and role of individual and professional factors in various aspects of human life is obvious. Working is not just a decent way of living, but an essential element of social basis and the source of meaning in people's lives. Obviously, the constructive role of job depends on the suitability of the occupation and the characteristics of the employee (1). Occupational factors refer to the cases or duties that faculty members are expected to do in their professional and occupational positions (2). Occupational attributes in designing a job was a superior attitude in the 1970 s and early 1980s. The attitude resulted from studies carried on occupational and motivational characteristics (such as self-regulation and feedback) has found an evolving form that has been considered explicitly individual differences place in employee's responses to a job and finally, theoretically, have been considered the characteristics of a job (3).Paying attention to the characteristics of occupations in the design of jobs has many benefits; it enhances growth and self-development, and work is designed in a way that stimulates internal motivation, because in this way, motivation is increased and functioning improves, and as a 
result, job becomes more productive and takes on a more humane character, and the negative effects of work such as replacement, absenteeism, and loss of time decrease. Both employees and the organization benefit from this; employees work better and become more self-reliant, and organizations become more productive. Individual factors also affect the social health of individuals. These factors refer to the characteristics of selfefficacy and personality type of individuals. Selfefficacy is one of the applied concepts in sociallearning theories or sociological-cognitive theories of professional behavior. Self-efficacy refers to the way an individual organizes and implements the practices needed to achieve the expected situations.

Personality type is a combination of personal characteristics and attributes that are used to measure individuals and distinguish humans from each other. One of the components affceted by professional and individual factors is social health. Social health is one of the main pillars of sustainable development and an integral part of flourishing and improving quality of life. In other words, health is a multidimensional and, at the same time, a very important activity. On the one hand, many factors play a role in creating and sustaining it, and they are the result of the participation of all executive agencies of a society, and on the other hand, the health issue has a significant impact on other sectors of society. Maintaining and promoting health is a prerequisite for moving in line with economic and social planning. Each society will enjoy a vibrant life when citizens have the desired physical, psychological and social health. This way, society can progress through evolution and achieve an acceptable level of development (4-5).In this research, we are trying to examine the role of individual and professional factors on social health of faculty members of Islamic Azad universities in East Azarbaijan, Iran. Therefore, the following research questions are formulated:

RQ1: Is there a significant relationship between the characteristics of the job and its components (feedback, freedom of action, importance in work, work identity and diversity in skills) with social health of the faculty members of Islamic Azad Universities?

RQ2: Is there a significant relationship between individual characteristics and its components (personality type and self-efficacy) with social health of faculty members of Islamic Azad universities? In the individual dimension, the researchers considered factors that emphasize the individual characteristics of the faculty members (2). In this study, two individual factors of self-efficacy and personality type have been investigated.
Another variable of the present study is the concept of health whose simplest definition is being healthy in terms of body, mind and soul. Social health is one of the key components of health and, at the same time, the most complex and controversial aspect of health, which encompasses social dimensions and well-being and plays an important role in the balance of human social life (6). Social health is a concept that refers to the relationship between the two concepts of health and society. Given that the community itself is a credit concept and its external truth depends upon the individuals who form it, individuals of the community should be studied more than anything else in the society. Social health is realized when families and individuals are relatively healthy and each citizen is responsible towards their community and finds their happiness in community health.

When social well-being is achieved, people will have incentive and happy spirits and, ultimately, the society will be happy and healthy (7). Having the right social thoughts and having a positive attitude toward the society is the first and most important stage of social health for social life which have, unfortunately, not received enough attention (8).

\section{Materials and Methods}

The present study is a correlational study investigating the role of individual and professional factors in social health of faculty members of Islamic Azad universities in East Azarbaijan, Iran. To this end, a total of 320 faculty members participated in the study. The variables of the study were job characteristics, individual characteristics, social health of faculty members, and personality type.

In order to collect the required data, the researcher designed a questionnaire which included three different sections (each measuring one of the variables), and each section was an adapted version of a standard questionnaire whose validity had been measured before. The results of Cronbach's alpha confirmed high reliability estimates for social health $(\alpha=.85)$, personality type $(\alpha=.89)$, self-efficacy $(\alpha=.96)$, job properties $(\alpha=$ .87 ), organization support $(\alpha=.86)$, organization trust (.83), and organization health $(\alpha=.89)$. In addition, the face validity of the questionnaire was corroborated by experienced professors and experts in the field. The first section of the questionnaire was designed to measure social health of the participants. In this section, there were 33 Likert-scale items ( 1 = strongly agree, $5=$ strongly disagree) which were designed according to Keyes theory (1998) (9). The subsections included 'social solidarity' ( 7 items), 'social acceptance' (7 items), 'social participation' (6 
items), 'social adaptation' (6 items), and 'social flourishing' (7 items).

Section two of the questionnaire, which had 25 items, investigated the personality type variable based on a yes/no question type. The items were adapted from Friedman and Rozanman (1974) (10). Based on the results of this section, individuals are divided into Type A or Type B personality types. While Type $A$ individuals are characterized as competitive, time urgent, hostile and aggressive, those individuals that fall into Type B category are more relaxed, patient and easy going. The third section contained 17 items ( $1=$ strongly agree, $5=$ strongly disagree) investigating the self-efficacy variable. These 17 items were all taken from Sher et. al. questionnaire which was designed to measure self-efficacy. The subsections included 'desire to initiate behavior' (6 items), 'resist barriers' (5 items), and 'the desire to continue trying to complete behavior' (6 items). The last section of the questionnaire was a 15-item section investigating the job characteristic variable ( $1=$ strongly agree, 5 = strongly disagree). The items were designed to measure the five components of the job characteristics variable, including 'job variety' (3 items), 'job identity' (3 items), 'job importance' (3 items), 'freedom of action' (3 items) and 'job feedback' (3 items). This section together with the subsections were adapted from the work of Hockman and Oldham (1980) (11).

The data were analyzed using the structural equation modeling in Amos software, and the following hypotheses were formulated for the research:
Hypothesis1: There is a relationship between the characteristics of the job and its components (feedback, freedom of action, importance in work, work identity and diversity in skills) with social health of the faculty members of Islamic Azad Universities and its components (social cohesion, social acceptance, social participation, social adaptation, and Social prosperity).

Hypothesis 2: There is a relationship between individual characteristics and its components (personality type and self-efficacy) with social health of faculty members of Islamic Azad universities and its components (social cohesion, social acceptance, social participation, social adaptation, and social prosperity).

\section{Results}

After collecting the data, the relationships between variables were first tested using the multiple correlation method. The table below presents the results of coefficient correlation between job characteristics and social health and the correlation coefficient between the components of job characteristics and social health.

According to Table1, there is a significant relationship between job characteristics and social health ( $P$-value $=0.002)$, and \% 43 of social health changes are explained by job characteristics. Furthermore, it reveals the correlation coefficients between the components of job characteristics and social health.

Table 1: Correlation coefficients between components of job characteristics and social health

\begin{tabular}{lcc}
\hline \multicolumn{1}{c}{ Variable } & Estimation (coefficient of determination) & significance level \\
\hline Job characteristics and social health & 0.430 & 0.002 \\
\hline Feedback with social health & 0.730 & 0.001 \\
\hline Freedom of action with social health & 0.464 & 0.001 \\
\hline Importance in working with social health & 0.764 & 0.000 \\
\hline Identity of working with social health & 0.423 & 0.008 \\
\hline Skills variety with Social Health & 0.568 & 0.012 \\
\hline
\end{tabular}

According to the above table, there is a significant relationship between the components of job characteristics and social health, and $p$-value for all the components is less than 0.05 , which confirms the significance of the relationships.
Tables 2 and 3 provide the information about the possible relationships between individual characteristics and its components (personality type and self-efficacy) with social health of faculty members of Islamic Azad universities.

Table 2: Correlation coefficients between individual characteristics and social health

\begin{tabular}{lcc}
\hline \multicolumn{1}{c}{ Test } & $\begin{array}{c}\text { Estimation of determination } \\
\text { coefficient }\end{array}$ & significance level \\
\hline $\begin{array}{l}\text { The relationship between individual } \\
\text { characteristics and social health of faculty } \\
\text { members }\end{array}$ & 0.583 & 0.001 \\
\hline
\end{tabular}


According to Table 2, it can be concluded that there is a significant relationship between individual characteristics and social health. The critical rate and significance level in Table 3 ( $P$-value $<0.001)$ confirm the relationship and $583 \%$ of the changes in social health are explained by job characteristics. Therefore, hypothesis 2 is confirmed.

Table 3: Results of correlation coefficients between the components of job characteristics and social health

\begin{tabular}{lcc}
\multicolumn{1}{c}{ Variable } & $\begin{array}{c}\text { Estimation of determination } \\
\text { coefficient }\end{array}$ & Significance level \\
\hline Personality type with social health & 0.621 & 0.008 \\
\hline Self-efficacy with social health & 0.589 & 0.012 \\
\hline
\end{tabular}

Moreover, as seen in Tables 4, there is a significant relationship between the components of individual characteristics and social health. The rate of $\mathrm{P}$-value for all the components is less than 0.05 , which confirms the significance of the relationships. Having analyzed the collected data, the following figure is obtained.

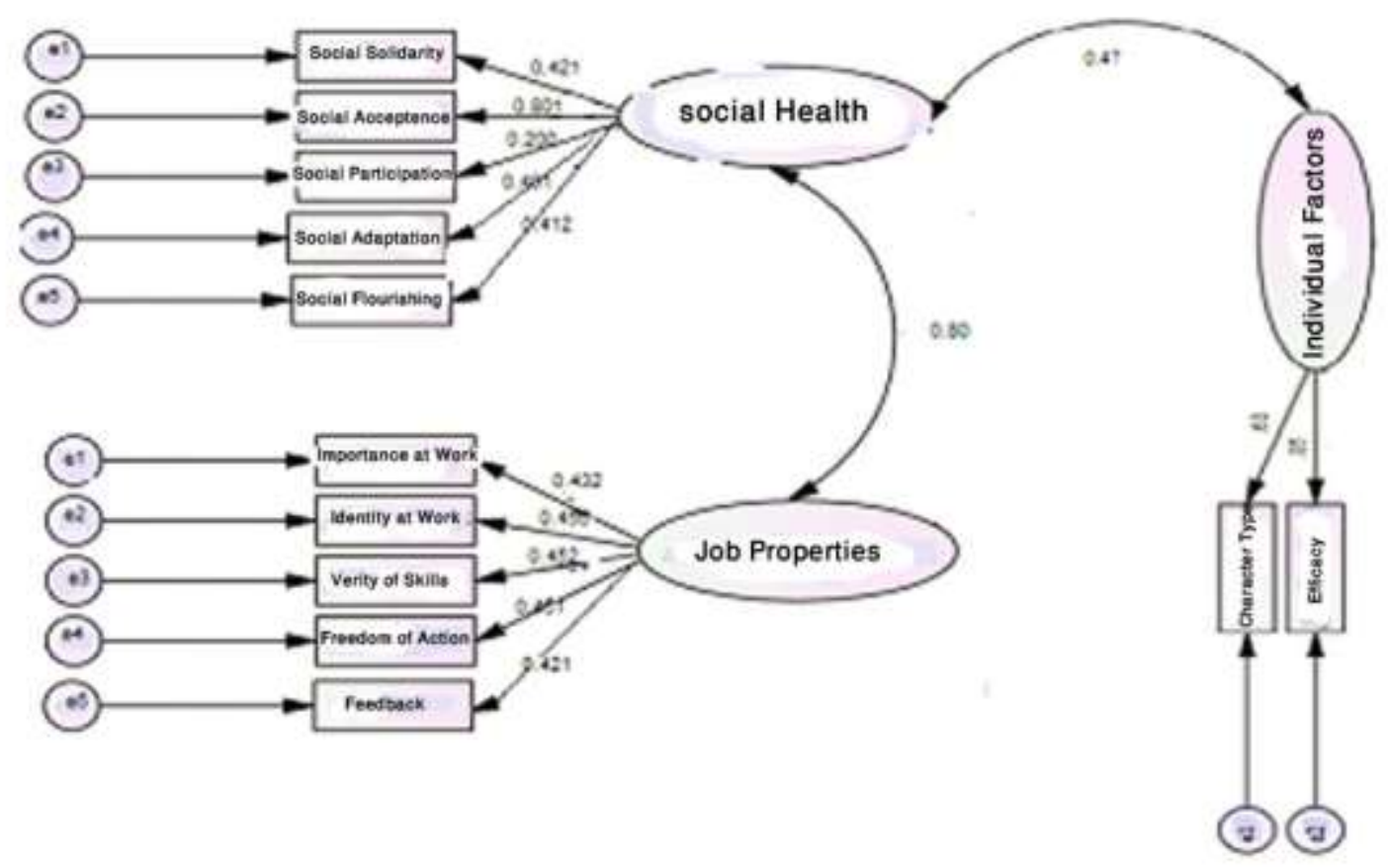

Figure 1: Structural Model of Individual and professional factors affecting social health of faculty members

As seen in Figure 1, the regression coefficient between social health and job characteristics is 0.8 , which indicates the positive effect of occupational characteristics on social health. The regression coefficient between individual factors and social health is 0.47 , and the weights of the components of professional characteristics and individual factors and social health are in a favorable position because their value is above 0.4 , and only the value for social acceptance is 0.2 , which is to rather weak. There is a meaningful relationship between the professional and individual characteristics and social health of the faculty members of Islamic Azad universities in East Azarbaijan, Iran.

\section{Discussion}

Individual and professional characteristics have a positive impact on success, performance improvement, and other behavioral variables in all organizations. Social health is an important component for the employees of every organization. Faculty members of the universities are among the influential people in the community, whose health affects the health of the community, particularly from a social perspective. The present study was carried out to investigate the effect of individual and professional factors on social health of faculty members of Islamic Azad universities in East Azarbaijan, Iran. The results of multivariate correlations and the structural equation modeling in 
Amos software showed that there is a meaningful relationship between professional and individual characteristics with social health. There is also a meaningful positive relationship between the components of professional and individual characteristics and the social health of faculty members.

As regards individual factors, two components of individual characteristics (i.e., personality type and self-efficacy) of the faculty members of the universities are investigated. Previous studies have confirmed the relationship between social health and individual characteristics. For example, Nikogoftar (2018) showed that there is a positive relationship between the gender role of masculinity and femininity with self-efficacy and social health components (12). Ajam states that there is a significant positive relationship between the components of social health and academic selfefficacy of students of University of Medical Sciences. Harirchi et.al (2013) showed that factors of personality explain social health (13). Willet et.al (2015) state that some personality traits predict social health because many traits, attitudes, and behaviors predicted four dimensions of Keyes' social health (14).

In addition to covering living expenses, a job has a direct relationship with the physical, mental, and social health of the individual, and it is the basis for satisfying many of his/her intangible needs. Mehrabian et.al (2016) show that there is a positive relationship between social health and job satisfaction (15). Most managers believe that those employees who enjoy good health and well-being and work in a safe environment have more job efficiency and satisfaction than other employees. It has also been proven that satisfied employees have better health and live longer. Several studies have shown that unsatisfied people who are not satisfied with their jobs are susceptible to various illnesses, from headaches to heart diseases.

Shahidi et.al (2016) showed that self-efficacy and organizational commitment correlated directly and positively with teaching quality (16). Among the dimensions of organizational commitment, emotional commitment and continuous commitment have a higher predictive power for teaching quality. There was also a meaningful positive relationship between organizational commitment and selfefficacy. Also, the faculty's demographic factors did not affect the self-efficacy and organizational commitment of professors. Shaveran et al (2011) showed that the faculty member's confidence and self-efficacy have an effect on collective selfefficacy and that there is a hidden relationship between the faculty members' trust and selfefficacy. There also is a significant positive relationship between trust and collective selfefficacy and the faculty's self-efficacy with collective self-efficacy (17).

\section{Conclusion}

The results of this study support the findings of other studies and shows that individual and professional characteristics have a positive influence on success, performance improvement, and other behavioral variables. Based on the findings of the study, there is a meaningful relationship among the variables. It can be concluded that there is a linear correlation among professional features, individual factors, and social health. The better relationships among the individual characteristic can lead to higher social health for faculty members.

Like any other study, the researcher encountered limitations, some of which were out of his control. Among the limitations, lack of similar studies and related resources in the Iranian context were the most important ones, which led the researcher to use English articles as resource. Furthermore, lack of budget and the time-consuming data collection process were other limitations of the study.

The findings of the current study suggest further studies to be conducted in the field to investigate the difference between the social health of faculty members with members of other organization. It is also suggested that more variables (such as age, gender, major of study, etc.) be added to confirm the proposed theory.

\section{Acknowledgement}

We would like to thank all faculty members of the Islamic Azad Universities in East Azerbaijan Province for their cooperation, the authorities of these universities for their coordination in collecting the data, and all those who helped us in this research. This article is based on the PhD thesis by Rahim Abdollahfam, a doctoral student at the Department of Educational Management, Tabriz Branch, Islamic Azad University, Tabriz, Iran.

Conflict of interest: None declared.

\section{References}

1. Safari Sh, Goudarzi H. Investigation of the relationship between personality traits and burnout among faculty members and personnel of Islamic Azad University of Azadshahr. Quarterly Journal of Educational Leadership \& Administration 2009; 3(3):85-101.

2. Nave Ebrahim A, Pourkarimi J. Presenting a Conceptual Model for Faculty Members' Development in Universities and Higher 
Education Centers. Journal of Research in Educational Systems 2009; 2(5):101-21.

3. Griffin RW, Welsh A, Moorhead G. Perceived Task Characteristics And Employee Performance: A Literature Review. Acad Manage Rev 1981; 6(4):655-64.

4. Griffin RW, Moorhead G. Organizational behavior. 10th ed. Boston, United States: Cengage Learning; 2011.

5. Robbins SP. Organizational behavior: concepts, controversies, and applications. 7th ed. New Jersey, United States: Prentice Hall; 1996.

6. Masomi S. Comparison of social health among ealdery in city and county. [MSc thesis]. Tehran: Allameh Tabatabie's University; 2016.

7. Vinus RD, Sheoran N, Maan N, Tewatia B. Potential benefits of herbal supplements in poultry feed: A review. Pharma Innov 2018; 7(6):651-6.

8. Bokharaei A, Sharbateain MH, Tavafi P. A Sociological Study of the Relationship between Happiness and Social Health: (A Case Study of the 18-30 Year-Old youths of the City Malayer). Social Development \& Welfare Planning 2016; 7(25):1-39.

9. Keyes CM. Social Well-Being. Soc Psychol Q 1998; 61(2):121-40.

10. Raina Elley $C$, Kenealy T. Lifestyle interventions reduced the long-term risk of diabetes in adults with impaired glucose tolerance. Evid Basad Med 2008; 13(6):173.
11. Hackman JR, Lawler EE. Employee reaction to job characteristic. J Appl Psychol 1971; 55(3):259-86.

12. Nikoogoftar M. Social Health and Self-Efficacy of Teachers with an Emphasis on Gender SelfConcept. Social Welfare Quarterly 2017; 17(64):261-91.

13. Ajam AA. The Predict of academic self- efficacy through social Well-Being of Students at University of Medical Sciences. Education Strategies in Medical Science 2016; 9(1):71-8.

14. Harirchi AM, Khedri B, Momeni Masuleh FS. Investigating the effect of personality traits on the level of social health of chemical veterans. Research Journal on Social Work 2014; 1(1):3970.

15. Mehrabian H, Harting J, Snoeijer JH. Soft particles at a fluid interface. Soft Matter 2016; 12(4):1062-73.

16. Shahidi N, Jafari $P$, Ghourchian N, Behboodian J. On the Relationship of Self-efficacy and Organizational Commitment to Teaching Quality of Faculty Members in Zone of Islamic Azad University. Quarterly Journal of New Approach in Educational Administration 2013; 4(15):21-43.

17. Shavaran SHR, Rajaeepour S, Kazemi I, Zamani BE. Determining Multi Relationships among Faculty Trust, Faculty Efficacy and Collective Efficacy at the universities. Quarterly Journal of Research and Planning in Higher Education 2012; 18(2):19-44. 